\title{
Serviço e Comunidade, Vetores para a Formação em Saúde: o Curso de Medicina da Uniderp
}

\author{
The Health System and the Community \\ as Vectors for the Preparation of Health \\ Professionals: the Medical Course at Uniderp
}

Paulo Eduardo Cabral Jose Lucio Martins Machado ${ }^{I I}$ Valéria Menezes Peixeiro Machado ${ }^{I I}$

Maurício Antonio Pompílio ${ }^{I}$ Joaquim Miguel Vinha Wilson Ayach ${ }^{I}$ Maria Cristina Iwama de Mattos ${ }^{\text {III }}$
PALAVRAS-CHAVE

- Educação médica;

- Aprendizagem baseada em experiência;

- Extensão comunitária;

- Serviços de saúde

- Saúde da família;

- Sistema Único de Saúde.

\section{KEY WORDS}

- Medical Educations;

- Problem-based learning;

- Community-institucional Relations;

- Health services;

- Family health;

- Single health system.

Recebido em: 27/04/2005

Reencaminhado em: 23/10/2006

Aprovado em:14/03/2007

374 REVISTA BRASILEIRA DE EDUCAÇ̄̃o MÉDICA
${ }^{I}$ Universidade para o Desenvolvimento do Estado e da Região do Pantanal, Mato Grosso do Sul, Brasil.

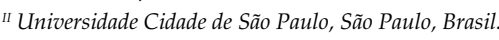

III Universidade Estadual Paulista, São Paulo, Brasil. 


\section{INTRODUÇÃO}

A América Latina, em particular o Brasil, sai dos anos 1990 com um quadro sanitário em que persistem grandes diferenças na distribuição dos fatores determinantes das condições de saúde, no acesso e na qualidade dos serviços prestados à população $\mathrm{O}^{1,2}$. Simultaneamente, a prática médica tem se pautado, cada vez mais, pela impessoalidade. A modificação desta prática profissional constitui, hoje, uma condição importante para se almejar a integralidade e a eqüidade do modelo de prestação de serviços de saúde.

Em passado recente, houve várias tentativas de modificar essa prática a partir da educação médica ${ }^{3-5}$, visando formar o médico "que o país necessita" ou o médico como agente de mudança social, porém não se tem conseguido superar os limites apontados. Não obstante, constatam-se alguns centros de formação de excelência, por meio de maior interação do processo educativo com a realidade na qual a escola médica se insere e mediante a promoção de formas mais ativas de aprendizagem.

Nos últimos anos, os países membros da Organização Mundial de Saúde (OMS) têm enfatizado, juntamente com as Associações Nacionais de Educação Médica, a necessidade de alinhar a prática e a educação médicas como ferramentas fundamentais para reverter aquele quadro ${ }^{2,6-10}$.

A América Latina apresenta uma estrutura com problemas de cunho social, epidemiológico e demográfico que impõem aos serviços de saúde novos e crescentes desafios ou demandas. Como parte desse panorama, há uma formação profissional médica em geral fragmentada, centrada em aspectos biológicos, superespecializada, privilegiando o cenário hospitalar.

Quando se detém a análise na gênese dos problemas de saúde, constata-se que, junto dos aspectos biológicos, são inúmeras as determinações sociais e psicológicas presentes no fenômeno saúde-doença, exigindo o diálogo entre as diferentes esferas do conhecimento, para dar conta de uma apreensão mais pertinente dos objetos insertos no universo da saúde.

Dessa forma, impõe-se contemplar, na formação profissional médica, a dimensão psicossocial do fenômeno saúdedoença, para que o futuro profissional de saúde tenha despertada a sua sensibilidade e, quiçá, a sua consciência, para as questões de ordem subjetiva e coletiva presentes em seu cotidiano de trabalho, tornando-se um agente promotor da elevação da qualidade de vida da população, que é, em última instância, um dos objetivos amplos das políticas públicas e, portanto, da educação ${ }^{5,11}$

Segundo o Plano Nacional de Extensão ${ }^{12}$, "a extensão é uma via de mão dupla", pela qual a academia dialoga com a sociedade, a teoria se confronta com a práxis, disseminando, apreendendo e reelaborando saberes, em um processo dialético, propiciador de "um trabalho interdisciplinar que favorece a visão integrada do social". Ele define a institucionalização da extensão como uma necessidade urgente e instiga as universidades a reformularem seus projetos pedagógicos, incorporando, de modo efetivo, as atividades de extensão universitária ao currículo. O caso do Programa Interinstitucional de Interação Ensino-Serviço-Comunidade da Uniderp (Pinesc) é um exemplo de institucionalização da extensão no currículo do curso de medicina.

\section{O CURSO DE MEDICINA DA UNIDERP/ANHANGUERA}

A Universidade para o Desenvolvimento do Estado e da Região do Pantanal (Uniderp/Anhanguera) tem sua missão voltada para o desenvolvimento de Mato Grosso do Sul e, particularmente, do Pantanal. Oferece um curso de graduação em medicina com um currículo inovador, capaz de responder a essa exigência e aos desafios contemporâneos.

Esse curso visa formar um profissional capaz de, concluída a graduação, assumir o exercício da medicina. Para tanto, impõe-se uma formação geral sólida, dotando o profissional de uma visão global da pessoa, das conexões entre as esferas biopsicossocial, do processo de saúde e doença, dos seus determinantes políticos e econômicos, garantindo-lhe competência técnica para resolver a maior parte dos problemas de saúde da comunidade em que for atuar. Elegeram-se métodos pedagógicos inovadores, nos quais o aluno ocupa o centro do processo de ensino-aprendizagem na condição de seu sujeito ativo. A inserção precoce do acadêmico na comunidade, junto aos serviços públicos de saúde, é a oportunidade para se apropriar tanto da lógica que preside a prestação daqueles serviços, como da natureza e particularidades da coletividade a que servem ${ }^{3,4,6,11}$.

Paralelamente à competência técnica, impõe-se estimular o aluno a firmar compromisso com a ética, entendida como um conjunto de valores que devem permear a atitude pessoal, cidadã e profissional, com vistas a ensejar uma postura de respeito ao outro e de acolhimento ao paciente que buscar a sua atenção, o seu serviço profissional ${ }^{13}$.

Outro aspecto central do curso é a sua vinculação com o Programa de Saúde da Família, a cujas equipes os estudantes se agregam, do primeiro ao oitavo semestre, para realizarem os módulos do Pinesc e, depois, no internato em atenção primária. Assim, desde o princípio de sua vida acadêmica, têm a oportunidade de conhecer o cotidiano tanto dos serviços de saúde, como das famílias a eles adstritas. Dessa forma, capacita-se o futuro profissional para o exercício da função de médico de família, como membro de uma equipe de profissionais 
de saúde em qualquer parte do País, já que o PSF tem âmbito nacional.

\section{O PINESC}

Sob essa perspectiva, foi concebido e implantado o Programa Interinstitucional de Interação Ensino-Serviço-Comunidade (Pinesc) ${ }^{14}$. Foi negociado e firmado um convênio entre a Prefeitura Municipal de Campo Grande e a Uniderp/Anhanguera, com a interveniência da Secretaria Municipal de Saúde, gestora plena do SUS, no qual se previram as condições de acesso ao serviço para os estudantes, bem como a designação de profissionais para acompanhá-los no período em que estivessem na Unidade Básica de Saúde.

Considerando que se trata de uma parceria entre uma universidade privada e um órgão público, procurou-se cercar o processo de todas as cautelas, para evitar a leitura segundo a qual se estaria privatizando um bem público. Esta precaução se fazia necessária, sobretudo naquele momento, 1999, quando o candente debate sobre a privatização de empresas públicas no País poderia provocar resistências à mera proposição do programa.

Logo, foi estabelecida uma forma de retribuição pecuniária aos profissionais dos serviços que se engajassem ao programa na qualidade de preceptores. E aí surgia um problema: não havia como vincular este profissional ao corpo docente como empregado da Uniderp, pois sua atuação deveria ocorrer, por definição, durante seu exercício como médico da rede municipal de saúde, ou seja, ele só poderia ser preceptor do programa se fosse detentor do cargo de médico da rede municipal de saúde e se estivesse exercendo esse cargo. Portanto, não havia como superpor, num mesmo espaço e horário, dois vínculos laborais distintos. Este problema foi equacionado por meio de uma cláusula do referido convênio, pela qual a Prefeitura repassa uma "gratificação de apoio à docência" aos profissionais integrantes do programa, cujo montante é pago pela universidade.

No plano operacional, adotaram-se medidas simples, mecanismos mínimos para viabilizar a consecução dos objetivos listados no convênio. Assim, definiram-se os canais de interlocução entre as partes, de modo a construir uma unidade de comando no âmbito de cada uma das instituições e evitar ruídos de comunicação, tão freqüentes quando não se tem definido quem responde por elas.

Paralelamente, elaborou-se a programação das atividades que seriam realizadas nos serviços, para garantir a unidade de ação do Pinesc. Esta evoluiu para um processo compartilhado, em que docentes do curso de medicina, preceptores e, após três anos, também alunos participam da construção des- sa programação, que deve ser observada por todos e, embora não seja uma rígida cláusula contratual, integra o corpo de instrumentos que norteiam a interação entre ensino, serviço e comunidade.

\section{O TRINÔMIO ENSINO-SERVIÇO-COMUNIDADE}

Para se implantar o ensino baseado na comunidade, é preciso abordar a complexidade do trinômio ensino-serviçocomunidade ${ }^{11}$ e dos segmentos extra-acadêmicos com os quais estudantes e docentes devem interagir. Não é simples propor esta interação, dada a resistência a este modelo. Primeiramente, há o estranhamento decorrente do confronto dos diferentes interesses postos em contato. Afinal, o docente e o estudante de medicina de uma universidade privada transitam num espaço, não raro, distante daquele dos trabalhadores em saúde. Estes, por sua vez, apesar de atuarem numa comunidade, nem sempre se identificam com as necessidades e aspirações desta. Fazer confluírem pontos convergentes destes três universos tão distintos é tarefa desafiadora, cujo roteiro de execução deve ser construído a partir de cada situação concreta, sem esquemas preconcebidos que possam prejudicar a percepção da realidade.

Outra dificuldade são as diferentes vertentes culturais em confronto, expressas tanto no plano organizacional, já que a interação se dá por intermédio de distintas instituições, com seus respectivos códigos, regimentos, finalidades e cultura institucional, como no plano individual, com pessoas portando bagagens culturais diversificadas, interesses específicos em síntese, biografias postas em contato por força do Pinesc, o que, em tese, pode desaguar em conflito.

Finalmente, há a incipiência do modelo e a inexistência de parâmetros consagrados, capazes de dotar o planejamento e execução das atividades educativas com a segurança das práticas calcadas na tradição. Embora possam ocorrer equívocos no ensino tradicional, porque nem todas as variáveis do processo ensino-aprendizagem podem ser totalmente controladas o tempo todo, eles já são previsíveis e, ao acontecerem, são equacionados com alguma facilidade. Não é o caso de programas inéditos, cujos desdobramentos têm de ser acompanhados pari passu à sua ocorrência, avaliados de imediato, para corrigir eventuais distorções ainda no curso do processo, visto que uma tentativa de correção a posteriori poderia ser inexeqüível.

\section{FASES DE IMPLANTAÇÃO DO PINESC}

O primeiro Caderno de Estudos do Pinesc ${ }^{15}$ já apontava que o programa era uma "oportunidade única para a inserção precoce do acadêmico na realidade concreta dos serviços de 
QUADRO 1

Seqüência de estruturação e implantação do Pinesc do curso de medicina da Uniderp de 1999 a 2006

\begin{tabular}{|l|l|l|}
\hline \multicolumn{1}{|c|}{ Ano } & \multicolumn{1}{|c|}{ Fases } & \multicolumn{1}{|c|}{ Local e Serviços } \\
\hline 1999 & concepção & Rede Municipal de Saúde Campo Grande (MS) \\
\hline 2000 & implantação & $\begin{array}{l}\text { Distrito Sanitário Norte de Campo Grande (MS) } \\
\text { Unidades Básicas de Saúde }\end{array}$ \\
\hline $\begin{array}{l}1^{\underline{o}} \text { semestre } \\
2^{\underline{o}} \text { semestre }\end{array}$ & $\begin{array}{l}\text { crise } \\
\text { mudança }\end{array}$ & $\begin{array}{l}\text { Distrito Sanitário Norte de Campo Grande (MS) } \\
\text { Unidades Básicas de Saúde } \\
\text { Rede Municipal de Saúde de Campo Grande (MS) } \\
\text { Equipes do PSF }\end{array}$ \\
\hline 2002 & consolidação & $\begin{array}{l}\text { Rede Municipal de Saúde de Campo Grande (MS) } \\
\text { Equipes do PSF }\end{array}$ \\
\hline $2003 / 2006$ & desenvolvimento & $\begin{array}{l}\text { Rede Municipal de Saúde de Campo Grande (MS) } \\
\text { Equipes do PSF }\end{array}$ \\
\hline $\begin{array}{l}2006- \\
2^{\underline{o}} \text { semestre }\end{array}$ & $\begin{array}{l}\text { Rede Municipal de Saúde de Terenos } \\
\text { Equipes do PSF }\end{array}$ \\
\hline
\end{tabular}

Fonte: Pinesc - Curso de medicina da Uniderp.

saúde pública e da comunidade, a qual é, indiscutivelmente, um locus privilegiado para o contato com situações que integrarão o seu futuro profissional, haja vista tratar-se de um dos maiores campos de atuação dos profissionais de saúde em nosso país".

Ao se esboçar o formato que teria o Pinesc, optou-se por delimitar uma área para a atuação dos acadêmicos, de forma a construir uma intervenção dotada de organicidade, a fim de se exaurir todo o potencial oferecido por este tipo de trabalho. Pretendia-se, entre outros objetivos, aferir o impacto produzido pelo programa, por meio da comparação de resultados entre a área onde estivesse implantado e as que não tivessem recebido o programa.

A cidade de Campo Grande tem quatro distritos sanitários. Definiu-se o Distrito Sanitário Norte como locus do Pinesc. O programa foi desenvolvido apenas nas oito Unidades
Básicas de Saúde (UBSs), sem se articular aos demais serviços do distrito. As UBSs apresentavam diferentes portes e precisaram ser tratadas diferentemente, pois, caso se propusesse um padrão uniforme para todas, haveria o risco de inviabilizar o trabalho.

Reunindo as regiões urbanas do Prosa e do Segredo, o Distrito Sanitário Norte contava com as UBSs apresentadas no Quadro 2.

Com efeito, a diversidade das UBSs e a disparidade do número de alunos lotados em cada uma delas trouxeram dificuldade, porque não havia experiência acumulada na atividade de preceptoria. Por conta disto, tornava-se mais complicado realizar o acompanhamento e avaliação de cada preceptor, pois não se tinha condições de saber se as dificuldades decorriam do seu perfil pessoal ou profissional, das peculiaridades da UBS ou do tamanho do grupo com que trabalhava.

QUADRO 2

Unidades de Saúde - Distrito Sanitário Norte - Campo Grande - 2000

\begin{tabular}{|c|l|c|c|}
\hline $\begin{array}{c}N^{\circ} \text { de } \\
\text { Ordem }\end{array}$ & \multicolumn{1}{|c|}{$\begin{array}{c}\text { Denominação Oficial } \\
\text { da Unidade }\end{array}$} & $\begin{array}{c}\text { No de } \\
\text { Alunos }\end{array}$ & $\begin{array}{c}\text { Denominação } \\
\text { Popular }\end{array}$ \\
\hline 1 & Centro Regional de Saúde Dr. Gunther Hans & Nova Bahia \\
\hline 2 & Unidade Básica de Saúde São Francisco & Nova Lima \\
\hline 3 & Unidade Básica de Saúde Dr. Ademar G. de Souza & Mata do Jacinto \\
\hline 4 & Unidade Básica de Saúde Dr. Willian Maksoud & Estrela do Sul & Marabá \\
\hline 5 & Unidade Básica de Saúde Marly T. B. Pereira & Coronel Antonino \\
\hline 6 & Centro Regional de Saúde Dr. Arthur de V. Dias & 7 & José Abrão \\
\hline 7 & Unidade Básica de Saúde Dr. Lilito Nasser & 10 & Vila Nasser \\
\hline 8 & Unidade Básica de Saúde Dr. Milton K. Chinen & 5 \\
\hline
\end{tabular}

Fonte: Secretaria Municipal de Saúde Pública de Campo Grande. 
A propósito, cabe registrar um equívoco cometido na forma de recrutamento dos preceptores. Supôs-se que, prestigiando-se a gerência da UBS na escolha deles, isto favoreceria a implantação do programa, porque, com esta medida, seria possível neutralizar uma eventual resistência à recepção de estudantes e docentes de um curso universitário. Mas algumas escolhas se deram por critérios afetivos ou políticos, o que comprometeu o desenvolvimento do Pinesc.

Uma das normas do programa prevê que, em princípio, o aluno deve "permanecer vinculado à mesma equipe de saúde durante os quatro anos do Pinesc, para realizar um mergulho cada vez mais profundo no seio da comunidade"13. Para isto, os estudantes visitam todas as UBSs, a fim de que formulem sua escolha com conhecimento in loco, medida que favorece seu comprometimento.

Na fase de implantação, foi estabelecida uma programação prescritiva, cronogramática, para que se obtivesse uma unidade de ação em meio à heterogeneidade de situações existentes. Os preceptores a observaram, apesar de algumas dificuldades.

\section{UMA CONJUNTURA DE CRISE — PRECEPTORES DAS UBSs}

Em 2001, além dos segundanistas, que passaram a freqüentar a UBS no período vespertino das terças-feiras, continuaram os primeiranistas a cumprir o Pinesc às quartas-feiras. Registre-se que, dos oito preceptores, dois eram médicos do PSF e os outros seis eram médicos de unidades básicas de saúde convencionais, com contratos de trabalho de vinte horas semanais, muitos deles habituados ao cumprimento de 16 consultas por jornada, independentemente do tempo despendido, não raro inferior às quatro horas diárias contratuais.

Assim, com exceção dos médicos de família, a maioria dos demais passou a ter dificuldade em atuar como preceptor do Pinesc em duas tardes da semana, pois quase todos tinham outras atividades laborais. Essa circunstância explica por que, mesmo tendo sido reajustada a gratificação paga pela preceptoria, esta deixou de ser interessante para os preceptores que não dispunham do tempo negociado para atender aos alunos.

Além dessa questão, havia, em alguns casos, incompatibilidade do preceptor com o perfil requerido, ou seja, pessoas que desestimulavam os acadêmicos, apontando apenas as dificuldades e os limites da atuação do SUS; pessoas que não demonstravam desempenho adequado no trato com os usuários e com outros membros da equipe do serviço; em síntese, pessoas destituídas dos requisitos mínimos para o exercício da preceptoria.

A situação era grave. Afinal, os preceptores são modelos em que se espelham os futuros profissionais durante a sua formação. O acompanhamento e a avaliação realizados demons- traram que, em algumas UBSs, o resultado era o inverso do esperado: os alunos demonstravam apatia e não conseguiam perceber o sentido da proposta de trabalho, nem tampouco apreender a razão do Pinesc.

O coordenador e os supervisores acadêmicos do programa, que têm responsabilidade direta, no âmbito da Uniderp/ Anhanguera, pelo seu desenvolvimento, resolveram mudar a lógica do Pinesc, abandonando o eixo da territorialidade, expressa pela intervenção no Distrito Sanitário Norte. Era uma proposta radical, mas necessária. Assim, transferia-se o eixo para a natureza do serviço, elegendo-se o Programa de Saúde da Família como espaço para a realização do Pinesc.

É preciso ter claro que os dois preceptores médicos de família realizaram um trabalho diferente, que envolvia os acadêmicos e respondia aos objetivos do Pinesc. Convém registrar ainda que, naquele momento, maio de 2001, atingira-se o número de 14 equipes de PSF em Campo Grande, o que permitia esta mudança de eixo.

Primeiramente, comunicou-se a gravidade da situação e a sua possível solução ao coordenador do curso de medicina e, depois de aceita por ele, ao reitor da Uniderp. Em seguida, discutiu-se a questão na Secretaria Municipal de Saúde (Sesau), que concedeu sua anuência para a mudança pretendida.

De imediato, reelaborou-se a programação para essa nova fase do Pinesc, com início no segundo semestre letivo. O coordenador do Pinesc comunicou à direção do Distrito Sanitário Norte, aos gerentes das UBSs e aos preceptores a mudança decidida. Depois, foram comunicados os alunos, cuja maioria precisou mudar de local. Houve uma forte reação, principalmente porque se deixava de observar o princípio da permanência por quatro anos em uma mesma UBS. Todavia, foram apresentadas as robustas razões que motivaram a decisão tomada, e, diante do fato consumado, os acadêmicos acabaram por aceitar a mudança.

\section{A ETAPA ATUAL DO PINESC}

A primeira providência adotada foi, em conjunto com os dirigentes da Sesau, mudar o critério de recrutamento dos preceptores. Estabeleceu-se o perfil mínimo a ser preenchido pelo profissional que viesse a integrar o quadro de preceptoria do Pinesc: responder adequadamente no exercício de sua função como médico de família; desejar conviver com acadêmicos do curso de medicina e auxiliá-los na interação a ser estabelecida com os demais membros da equipe de PSF e com a comunidade usuária dos serviços; entender o Sistema Único de Saúde como um processo em construção, no qual ele é ator privilegiado - em síntese, alguém identificado, inclusive ideologicamente, com o projeto pedagógico do curso de medicina da Uniderp/Anhanguera. 
QUADRO 3

Módulo Pinesc - Distribuição de alunos do curso de medicina por ano de curso, unidades de saúde e preceptores, de 2000 a 2006

\begin{tabular}{|c|c|c|c|c|}
\hline Ano & UBS & Equipes de PSF & Pinesc & Preceptores \\
\hline 2000 & 8 & 2 & $1^{\mathrm{o}}$ ano & médicos \\
\hline $2001-1^{\circ}$ semestre & 8 & 2 & $1^{\circ}$ e $2^{\underline{O}}$ anos & médicos \\
\hline $2001-2^{2}$ semestre & 6 & 8 & $1^{o}$ e $2^{o}$ anos & médicos \\
\hline 2002 & 9 & 12 & $1^{\circ}, 2^{\circ}$ e $3^{\circ}$ anos & médicos \\
\hline $2003 / 2006$ & 13 & 16 & $\begin{array}{l}1^{\circ} \text { e } 2^{o} \text { anos } \\
3^{\circ} \text { e } 4^{\underline{o}} \text { anos }\end{array}$ & $\begin{array}{l}\text { enfermeiros /médicos } \\
\text { médicos }\end{array}$ \\
\hline
\end{tabular}

Fonte: Pinesc - Curso de medicina da Uniderp.

A escolha de preceptores passou a ser feita pelo coordenador do Pinesc e pela dirigente do Programa de Saúde da Família, conjuntamente, ouvidos os supervisores acadêmicos.

Como a vinculação do aluno deixava de ser com a UBS e passava a ser com a equipe de PSF, pôde ser estabelecido o número de oito estudantes para cada preceptor, o que favoreceu a avaliação dos preceptores, uma vez que todos passaram a ter uma equipe de tamanho igual. Para evitar tumulto nas UBSs, tem-se procurado restringir a presença do Pinesc, no máximo, a duas equipes por UBS.

Em 2003, quando se completou o efetivo de alunos dos quatro anos do curso de medicina, eram necessários 16 preceptores e só havia 14 médicos de família com perfil e/ou dispostos a assumir a preceptoria. Frente ao impasse, decidiu-se agregar duas enfermeiras de equipes de PSF, em UBSs onde há outra equipe ligada ao programa, com o médico como preceptor, para atuarem com alunos do primeiro e segundo anos, uma vez que a programação dos quatro primeiros semestres se calca muito mais na atuação de um profissional de saúde do que na figura do médico (Quadro 3).

\section{PROGRAMAÇÃO DO PINESC}

A programação do Pinesc, a par de seu conteúdo específico, em muitos momentos se articula com outros componentes curriculares, na medida em que a comunidade e a UBS, por serem espaços de aprendizagem privilegiados, tornam-se um cenário que deve servir não só ao Pinesc, mas ao curso como um todo.

A organização curricular do curso de medicina da Uniderp, nos quatro primeiros anos, é constituída por seis módulos temáticos ao ano, nos quais se discute a teoria, acompanhada pelas atividades em laboratório dos módulos longitudinais de Habilidades Médicas e de Habilidades Gerais (Comunicação e Práticas Integradas) e pelo do Pinesc.
No Pinesc, durante os dois primeiros semestres, o aluno deve apreender a rotina de funcionamento da UBS, tomar o primeiro contato com os programas de saúde desenvolvidos, com a lógica de funcionamento do SUS, bem como estabelecer uma primeira aproximação com a coletividade. A partir do terceiro semestre acontece a adoção de famílias, pelo aluno, para acompanhá-las em seu desenvolvimento e necessidades. $\mathrm{O}$ aluno faz consultas domiciliares supervisionadas; traça o perfil epidemiológico da microárea em que atua para levantamento de problemas, que podem condicionar a seleção de tema para elaboração de projeto de pesquisa, a ser desenvolvido no módulo de Habilidades Gerais; desenvolve atividades de prevenção articuladas aos programas realizados pela equipe; vivencia noções de ética no cotidiano da equipe de PSF e no trato com a coletividade.

Inicialmente, as atividades tinham sido concebidas de forma que os problemas de saúde da comunidade fossem aprendidos por meio de problematização. No entanto, para que o programa pudesse ser compreendido e utilizado pelos preceptores e alunos que vivenciavam pela primeira vez o ensino na comunidade, em 2000 seguiu-se um cronograma rigoroso. Já em 2001, ao contrário, a programação foi muito aberta, sendo levados aos preceptores apenas tópicos principais a serem abordados durante o ano.

A partir de 2002, a programação encontrou um ponto de equilíbrio. Indicam-se as atividades a serem cumpridas, sem, contudo, amarrá-las a um cronograma rígido. Apresenta-se o conjunto de atividades a serem realizadas, numa seqüência que poderá ser alterada em função das circunstâncias do serviço ou mesmo de situações relativas à coletividade. O preceptor tem a liberdade de reorganizar a programação definida, bem como de incluir, suplementarmente, outras atividades que entenda factíveis e oportunas, sem se preocupar com o 
calendário, bastando ser cumprida a programação proposta, independentemente da ordem em que tiver sido realizada.

Em 2003, os componentes curriculares de Práticas Integradas e Comunicação passaram a utilizar o cenário do Pinesc como recurso para o desenvolvimento de alguns tópicos de sua programação. As atividades de Práticas Integradas complementam os assuntos discutidos em tutorias. As habilidades de comunicação vão trabalhando gradativamente com os alunos as abordagens do paciente, para que possam aprender com mais facilidade a realizar entrevista, visita domiciliar, uma adequada anamnese e atividades de educação em saúde.

Esse diálogo entre os diferentes componentes do curso foi importante porque fortaleceu a imagem do Pinesc para os alunos, já que as potencialidades do serviço e da comunidade deixam de ser mencionadas somente pelos preceptores, supervisores acadêmicos e coordenador do Pinesc, passando a ser reconhecidas, proclamadas e exploradas por outros segmentos do curso, que passam a vivenciar mais intensamente a vertente do ensino baseado na comunidade.

\section{A EXPANSÃO DO PINESC}

Uma vez formada a primeira turma de alunos, da qual duas egressas atuam como médicas de família concursadas e também como preceptoras, concluiu-se pela necessidade de ampliar a área de abrangência do Pinesc. No segundo semestre de 2006, celebrou-se um convênio com a Prefeitura Municipal de Terenos, cidade contígua a Campo Grande, que abre novas perspectivas para o curso de medicina da Uniderp/ Anhanguera.

De início, ao invés de se gratificar um preceptor, acordou-se fazer essa retribuição sob a forma de consultas especializadas no Centro de Especialidades Médicas da Uniderp — Cemed, ambulatório-escola de atenção secundária, clínica e cirúrgica, visando fortalecer o sistema municipal de saúde, já que em Terenos há um déficit de atendimento nessa área. Estão previstos, também, atendimentos no complexo policlínico odontológico, no centro de reabilitação e na clínica de psicologia, órgãos suplementares da universidade.

Para o ano cogita-se experimentar um novo modelo de organização do módulo, que prevê colocar duplas de estudantes, de todos os semestres, todos os dias da semana. Pretendese comparar os resultados entre os dois modelos, visando ao aprimoramento do programa.

\section{ALGUNS PROBLEMAS A SUPERAR}

O processo de construção do Pinesc ainda está em curso. É certo que algumas práticas já estão consolidadas, tem-se conseguido um acúmulo importante, atingiu-se uma atitude amadurecida no que concerne à avaliação do programa. Em que pesem estas conquistas, não se perdem de vista problemas que ainda persistem.

Hoje, o Pinesc atua no curso de medicina com 16 equipes de PSF, cada qual com dois grupos de alunos, de semestres diferentes, em dias da semana diferentes. São 32 grupos com a média de oito alunos por grupo. No oitavo e nono semestres os grupos se subdividem em dois de quatro alunos, com o mesmo preceptor, em dias diferentes da semana. Evidentemente, um programa desse porte, que envolve cerca de 300 pessoas de diferentes instituições, em diferentes lugares, pode gerar problemas. Quando eles acontecem, o supervisor acadêmico, que com uma freqüência mínima quinzenal, percorre todas as UBSs e se encontra com todos os grupos, ao detectar uma dificuldade, procura encaminhar a solução. $\mathrm{Na}$ hipótese de não conseguir, traz a questão ao coordenador do programa, que, demandado, intervém para buscar a composição do conflito.

Quase sempre, as maiores dificuldades têm decorrido da falta de profissionais com os requisitos do perfil mínimo. Há, ainda, os que, instáveis, assumem o compromisso para, logo em seguida, deixarem o PSF. Enfim, estas situações escapam ao controle das instituições envolvidas, pois, mesmo a Secretaria Municipal de Saúde (Sesau) não dispõe de mecanismos para monitorar, prevenir ou impedir que aconteçam.

Quando ocorre a saída de um preceptor, procura-se, na medida do possível, negociar com a dirigente do PSF a substituição por um profissional que preencha o perfil, evitando que o grupo tenha de ser removido para outra UBS e, dessa forma, se perca todo o investimento realizado na área. Caso essa possibilidade não exista, e mais de uma vez aconteceu, a saída é procurar outro preceptor e transferir os alunos para uma nova UBS. Não é a melhor solução, porém, como não se pode intervir na dinâmica do serviço, é preciso ajustar-se à realidade e trabalhar com os alunos a sua habilidade de se adaptar às novas situações.

O Pinesc pressupõe o trinômio ensino-serviço-comunidade e, nessa perspectiva, ele ainda não conseguiu se desenvolver plenamente. Constata-se a hipertrofia do binômio ensino-serviço, que foi capaz de criar um espaço dotado de organicidade, no qual se dá a sinergia entre os interesses da academia e os do SUS, numa comunhão de objetivos convergentes que, a despeito das distintas identidades e finalidades institucionais, integram-se numa ação vigorosa que repercute positivamente tanto no ensino como no serviço. Frise-se, contudo, que o mesmo não acontece com o terceiro elemento do trinômio: a comunidade.

Aqui, é preciso esclarecer que um dos fatores característicos da coletividade campo-grandense é a acentuada mobili- 
dade espacial dos integrantes dos estratos subalternos. Sendo uma sociedade com forte dinâmica demográfica e uma cidade ainda em franca expansão, as pessoas mais fragilmente articuladas à sua economia se transferem com muita facilidade de uma parte para outra da cidade ou mesmo para fora do município. Esse dado explica, em parte, a incipiência dos movimentos sociais de diferentes naturezas, que têm grandes obstáculos à sua estruturação. Registre-se, também, o passado ainda muito recente do mando oligárquico, característico do desenvolvimento político local, que acaba por inibir a emergência de novas lideranças ou a consolidação de lideranças autônomas. Esses fatores dificultam a identificação do ethos imprescindível à estruturação comunitária, para que seus membros se reconheçam como partícipes de um corpus orgânico, com finalidades e objetivos comuns, dotado de identidade própria, ou seja, uma comunidade efetiva, capaz de se reger com autonomia ${ }^{16}$.

Ao Pinesc resta o desafio de alargar a sua presença na coletividade campo-grandense e, mais do que isso, implementar a interação da coletividade com os serviços de saúde e com os membros da universidade, de modo a contribuir para que esses grupos, de fato, se constituam como comunidades, revestindo de maior legitimidade a ação até aqui desenvolvida.

\section{PAVIMENTANDO O CAMINHO DO INTERNATO EM ATENÇÃO PRIMÁRIA}

Em que pese não ter sido planejado com o propósito de se articular com o estágio supervisionado, o Pinesc acabou por constituir um importante elemento para treinar o olhar e exercitar a prática do acadêmico em relação ao nível de atenção primária à saúde da população.

Para o serviço e para a coletividade, o estágio supervisionado funciona como uma espécie de retribuição do curso de medicina da Uniderp/Anhanguera aos aliados que se dispuseram a assumir a parceria necessária à realização do Pinesc. Nessa etapa, ainda que o estagiário usufrua da riqueza que serviço e comunidade têm, ele pode, simultaneamente, oferecer alguma colaboração efetiva para a equipe de PSF e, por extensão, à comunidade, sob a forma de prestação de serviços que já é capaz de realizar, sob a supervisão do profissional médico. E ele o faz com razoável segurança, porque dispõe de familiaridade com aquele universo, propiciada pela experiência do Pinesc, desenvolvida ao longo dos quatro anos precedentes. Os frutos são visíveis, e tudo indica ser um processo irreversível.

Cabe aludir ao internato regionalizado, com sextanistas, realizado em parceria com prefeituras de municípios do interior de Mato Grosso do Sul e com a Fundação Nacional de Saúde (Funasa), que atende, entre outros segmentos, às popu- lações indígenas e de assentados rurais, ambas muito representativas da realidade regional.

\section{À GUISA DE CONCLUSÃO}

O Pinesc tem uma forte inspiração nos princípios norteadores do SUS e, como ele, é também um processo ainda em construção. Igualmente, encontra-se inacabado e, portanto, não pode ser avaliado como se fosse algo pronto. Mesmo assim, tem-se uma série de elementos que permitem afirmar tratar-se de uma iniciativa instigante, que gerou uma experiência bastante rica e poderá consolidar-se no fecundo terreno do cotidiano da população usuária dos serviços de saúde, dos trabalhadores que nele atuam e da academia, que deve formar profissionais habilitados a transitar nesse universo e, mais, capazes de transformá-lo para melhor.

Há problemas, e não são poucos. Todavia, longe de serem um fator de desestímulo, convertem-se em fonte motivadora da ação, que deve se voltar para a superação dos mesmos. À medida que se conquistem novos patamares de convivência entre diferentes esferas sociais, novos graus de excelência dos serviços, novas perspectivas para a formação de quadros profissionais e gestores, poder-se-á estabelecer o radical exercício da cidadania e o inalienável direito à vida plena como paradigmas maiores da práxis transformadora, em direção a uma sociedade justa, fraterna e solidária.

\section{REFERÊNCIAS}

1. Almeida CM. As reformas sanitárias dos anos 80: crise ou transição? Rio de Janeiro; 1995. Mestrado [Dissertação]ENSP/FIOCRUZ.

2. Chaves MM, Rosa AR. Educação Médica nas Américas, o desafio dos anos 90. São Paulo: Cortez; 1990.

3. Walton H. Medical education world-wide: a global strategy for medical education. Med. Education 1993; 27: 394-8.

4. Almeida MJ. Educação médica e saúde: limites e possibilidades das propostas de mudança. São Paulo; 1997. Doutorado [Tese] — Faculdade de Saúde Pública/USP.

5. World Health Organization. Implementation of the global strategy for health for all by the year 2000, second evaluation : And eighth report on the world health situation / Implementation of the global strategy for health for all by the year 2000, second evaluation : And eighth report on the world health situation. Geneva; World Health Organization; 1990. v. 52

6. World Federation for Medical Education. The Edinburgh Declaration. World conference on medical education. Edinburgh, Scotland, Report. Edinburgh, Scotland; 1988. p. 7-12. 
7. World Federation for Medical Education. Proceedings of the World Summit on Medical Education. Med. Education 1994; 28 (Suppl 1):142-9.

8. Boelen C. Towards Unity for Health-Challenges and opportunities for partnership in health development: a working paper. Geneva: World Health Organization; 2000.

9. Boelen C. Towards Unity for Health: case studies. Geneva: World Health Organization; 2001.

10. Silva J. Interação Escola Médica-Serviços. Cadernos da ABEM 2004; 1: 9-11.

11. Kisil M, Chaves M eds. UNI Program. W.K.Kellogg Foundation and the Network of Community-Oriented Educational Institutions for Health Sciences; 1995.

12. Brasil. Ministério da Educação. Secretaria de Ensino Superior. Fórum de Pró-Reitores de Extensão das Universidades Públicas Brasileiras. Plano Nacional de Extensão; 2000 / 2001, p. 5.

13. Cabral PE, Koadjoglanian VL, Barbier CP, Freitas LSS, Novaes CJ, Mattos MCFI. Interação ensino-serviço-comunidade: uma ferramenta para a integralidade. In: Pinheiro R, Ceccim RB, Mattos RA. Ensino-Trabalho-Cidadania: novas marcas ao ensinar integralidade no SUS. 2 ed. Rio de Janeiro: IMS/UERJ-CEPEC-ABRASCO; 2006. p.57-69.

14. Projeto Pedagógico do Curso de Medicina da UNIDERP, 1999 e 2004.

15. Cabral PE org. Caderno de Estudos do PINESC: Programa Interinstitucional de integração Ensino-Serviço-Comunidade - PINESC. 2.ed. Campo Grande, MS: Ed. UNIDERP; 2003 (Caderno de Estudos 283). p. 5.

16. Cabral PE, Iwama de Mattos MCF. Organização comunitária: desafio à mobilização. Olho Mágico 2005; 12(2): 104.

\section{CONFLITOS DE INTERESSE}

Declarou não haver

\section{ENDEREÇO PARA CORRESPONDÊNCIA}

Paulo Eduardo Cabral

Rua Nova Era, 480

Bairro Miguel Couto - Campo Grande

CEP. 79003-027 / MS

E-mail: cemed@uniderp.br 